\title{
Enlivening Political Science Courses with Kolb's Learning Preference Model*
}

\author{
Kathy L. Brock, Wilfrid Laurier University \\ Beverly J. Cameron, University of Manitoba
}

$M$ ost political science professors hope their courses will produce graduates with well-developed critical-thinking and problem-solving abilities, but many report frustration at not being able to meet this goal with all, or even most, of their undergraduate students. Among the many possible reasons for this frustration is a mismatch between the professor's learning preferences, which may determine his or her teaching style, and the students' learning preferences, which may affect their level of comprehension of material covered in the course. Learning preference mismatches may cause students to perform below their potential, earn political science the reputation of being a difficult, or worse, arbitrary subject, and reduce the professor's enthusiasm for teaching. Once these mismatches are identified and understood, they can be easily counteracted, usually without substantial course reorganization.

Individuals process information, learn concepts, and solve problems in different ways. An individual's learning preference is "a personally preferred way of dealing with information and experience that crosses content areas" (Kruzich, Friesen, and Van Soest 1986). There is no

Kathy L. Brock is an associate professor of political science at Wilfrid Laurier University. Her research and teaching interests include rights, the constitutional process, comparative federalism, aboriginal issues, and Canadian politics.

Beverly J. Cameron has a B.A. and M.A. in economics and a Ph.D. in higher education. In 1991 she was awarded the national $3 \mathrm{M}$ Teaching Fellowship for her teaching and leadership accomplishments. She is now director of University 1 , an innovative program that allows first-year students at the University of Manitoba to explore career and academic options before committing to a faculty program. "best" learning preference, there are just differences. This article examines learning preferences within the context of Kolb's Experiential Learning Model, and illustrates how learning preference mismatches in political science courses may be neutralized.

\section{Kolb's Experiential Learning Model}

There are a variety of models and classifications faculty and students can use to identify and understand their teaching and learning preferences (Keirsey and Bates 1984; ${ }^{1}$ Reinert $1976^{2}$ ). Of these, Kolb's Experiential Learning Model lends itself particularly well to classroom application (Kolb 1984, 1988).

Kolb's model has been widely used, and is respected for its validity and reliability. The model has also been the subject of extensive follow-up research in educational settings (Kolb 1976, 1984, 1988).

In Kolb's model, the process of learning is divided into four stages, all of which must be gone through for learning to be most effective (Smith and Kolb 1985). A brief description of the stages follows.

1. Concrete experience (CE) provides the basis for the learning process. Lessons at this stage engage the individual personally and learning relies on openmindedness and adaptability rather than a systematic approach to the situation or problem.

2. Reflective observation (RO) makes sense of the experience. In this stage, students consider their concrete experiences from a variety of perspectives and articulate why and how they occurred. Learning occurs as a result of patience, objectivity, careful judgment, and observation. Reflection helps students break their experiences into parts and to categorize them for use in the next stage of learning.

3. Abstract conceptualization (AC) assimilates and distills the observations and reflections into a theory or concept. In this stage, students come to understand the general concept of which their concrete experience was one example by assembling their reflections on the key parts of their experience into a general model. Abstract conceptualization requires students to use logic and ideas, as opposed to feelings, to understand situations and problems. Students can require considerable help from the text and instructor to proceed through this stage.

4. Active experimentation (AE) tests the theories and leads into new experiences. In this step, students use the theories they developed during the abstract conceptualization stage to make predictions about the real world and then act on those predictions. Students' actions, of course, are a new concrete experience. The learning cycle begins anew.

Instructors have countless opportunities for leading students through all four stages of the learning model in political science courses. The key to planning lessons that take students full cycle is to note that the second word in each of the four stages' names indicates what the learner experiences. The learner begins by having an experience that involves him or her in a situation (experience) and then reflects on the experience from several perspectives 
(observation). From those reflections, the learner draws concepts or conclusions and formulates them into theories or models (conceptualization) that lead them to experiment or act (experimentation).

\section{Kolb's Learning Preferences ${ }^{3}$}

Kolb found that learners typically did not use all four learning stages equally, but preferred to concentrate on one or two of them. He identified four learning preferences, each of which shows learners being most comfortable in a different pair of learning stages. ${ }^{4}$ Based on responses to a set of questions called the LearningStyle Inventory (LSI), Kolb (1988) described the four learner preference groups as divergers, assimilators, convergers, and accommodators. Understanding the preferences is critical to understanding how students may respond to lessons designed specifically for each stage.

Kolb's descriptions of the learning preferences can be summarized briefly. Divergers prefer learning through concrete experience and reflective observation. They may be particularly adept at viewing a situation or problem from many perspectives and developing imaginative solutions, in other words "brainstorming." Assimilators favor abstract conceptualization and reflective observation. These individuals are often able to pull together very different observations into an explanation or theoretical model. They tend to enjoy abstract assignments, such as creating action plans to solve problems, but are less interested in actually implementing the plan devised. Convergers learn best through abstract conceptualization and active experimentation. Their strength lies in the practical application of ideas. They tend to prefer concrete answers to gray areas or open possibilities and will organize their thinking to use hypothetical-deductive reasoning to focus on specific problems. The dominant learning preferences of accommodators are concrete experience and active experimentation. Accommodators tend to be risk takers who thrive on action and new experiences. They may be more comfortable relying on information from others than are individuals with other learning preferences.

These "doers" often excel in situations that require adaptation to immediate circumstances. If a plan they are using does not fit the facts, they will discard it rather than reexamine the facts.

Individuals with similar learning preferences tend to gravitate toward certain academic disciplines and professions (Kolb 1988). This may occur because instructors in particular disciplines teach to one preference and/or prepare assignments best completed by individuals with a particular learning preference. In this way, established members of a discipline may unconsciously reproduce themselves by teaching only to undergraduates who think as they do while alienating or discouraging students with different learning preferences. In the case of political science, where research indicates that there is a diverger learning preference, it would follow that success in political science courses comes most easily to diverger students. ${ }^{5}$

While it may or may not be desirable to attract graduate students who share the preferences of a ma- jority of their future colleagues, it is unlikely that academic departments want to sort students by learning preference at the undergraduate level. Teaching to all styles is important if for no other reason than allowing students to become adept at only one learning process would limit their development of effective thinking skills and problem-solving abilities. If political scientists want to attract more students to undergraduate political science courses, if the political science profession doesn't just want to clone itself, and if faculty want to teach students to become effective thinkers and problem solvers, it is worth examining the way political science is taught using a learning model.

One way to facilitate learning among students whose preferences do not match their professor's is to train professors to teach to the full range of preferences; to encourage instructors to take students through all four of Kolb's learning stages. Not only would this kind of teaching encourage more students to take political science courses beyond the introductory level, it would, according to Kolb, lead to graduates with more highly developed thinking and problem-solving skills.

\section{Implications of Using the Experiential Learning Model in the Classroom}

\section{Concrete Experience}

Teaching techniques that provide students with concrete experiences include in-class demonstrations, lectures with anecdotes, simulations, ${ }^{6}$ storytelling, jokes, cartoons, newspaper articles, statistical correlations with unexpected results, and films. Each can engage students' minds and emotions. The more personally relevant they find the concrete experiences, the more likely students are to become involved in the situation. Conversely, concrete experiences also provide students with chances to learn to relate their academic learning to the "real world" and, thus, appreciate it even more. ${ }^{7}$

An example of a relevant concrete experience is having students describe their first voting experience or 
involvement in a political campaign. Did they vote on policy or personality? Was the ballot clear or confusing? Did they get involved in a campaign or were they passive observers? Alternatively, the professor could discuss a recent election and the results in the students' home constituencies. If discrimination and representation are important themes in the course, the professor could encourage students to consider what role the race, gender, sexual orientation or religion of the candidates and the voters in the constituency played in determining the outcome of the election.

\section{Reflective Observation}

Techniques that provide opportunities for reflective observation include leading or arranging discussion and brainstorming sessions, asking rhetorical questions in lectures, providing questions related to course readings, and/or asking students to keep journals or write logs as they reflect on political situations or policies. In a large lecture class, where full-class discussion opportunities are limited, students can be requested to bring pads of paper to class to answer instructor-posed questions. For example, ask three to five questions per class period, invite students to record their reflections or observations, and collect the pads every two weeks to ensure that students are recording reflections. The "reflection pads" are usually marked less for quality and more for the presence of reflections

(Grasha 1997).

Reflective observation most engages students who are divergers and assimilators. In a course on elections, an instructor might lead students into this stage by asking them to ponder why some candidates succeeded and others failed and requiring them to record their reflections. Short presentations of these comments would enliven class.

\section{Abstract Conceptualization}

Abstract conceptualization can be fostered through model-building assignments, asking for critiques of models in the literature, assigning readings and/or providing analogies or descriptions of models and theories in lectures. The abstract conceptualization phase of the learning process lends itself to demonstrations of intellectual modeling by the instructor in lectures. It is very important that stu-

dents observe the instructor "thinking out loud," for it is by seeing the instructor's mind at work that students learn how to think like political scientists. When instructors only present conclusions or solutions to problems, many studentsespecially those without a matching learning preference-find it diffcult to understand or replicate the processes that result in higherlevel learning.

Some students in political science courses may resist assignments requiring abstract conceptualization and many will groan when asked to work with or develop theories and models, but this stage of learning can be made attractive even to the most emphatic of divergers. For example, a professor could analyze a reading in class by having students point out the underlying assumptions of the model of analysis. Alternatively, or additionally, a professor might divide students into small groups assigned to employ contrasting sets of assumptions or models to interpret an article. In an elections course, the students and professor could discuss and analyze an article written from a liberal, pluralist perspective. Small groups could then reexamine the article's conclusions using assumptions from a neo-marxist and class-based model of election behavior, or feminist theory, or critical race studies or neo-institutionalism. Then, in a plenary session, each group could compare the results to assess the strengths and weaknesses of the different approaches. Alternatively, through open discussion and debate, the professor could use the party results and voter preferences to define the national political culture or modify a theory of voting behavior.

Active Experimentation

Activities that encourage active experimentation include field work or labs, projects, assignments, case studies, simulations, and model testing. The emphasis is on "hands-on doing"-using models or theories to provide practical or useful outcomes. Introductory texts often contain practical exercises or case studies that can be used in theory testing exercises. Also, simulation exercises are becoming more available (see note 6).

In a political science course coincident with an election, students could be asked to project the outcome of the election or the vote in a specific district using the polling data generated over the past year by the major polling firms or an analysis of the social, political, and income profiles of the targeted area. They could then track the fortunes of the parties as the election campaign developed and adjust their model, offering final predictions on voting day (active experimentation). When the actual election results were known (concrete experience), the students could be asked to reflect on the possible explanations of the results (reflective observation), and to analyze their model and its accuracy as well as the strengths and limitations of voting behavior theory (abstract conceptualization). Further, students could be required to use the model of voting behavior from the previous task to study a particular electoral district during the election and see if their initial suspicions about the strengths and weaknesses of the model hold. 
While similar learning exercises may appear in two or more categories (simulations, for instance, provide both concrete experience and foster active experimentation), the purpose of the exercise varies according to the learning process it is meant to activate. For example, a model simulation of Congress could give students an appreciation for the power dynamics among the various actors in the concrete experience stage, or it could be used to verify a rational choice or institutionalist theory of political decision making in the active experimentation stage of the learning cycle.

The example exercises provided for each of the learning stages are designed to move students from the passive "receiver" role to the active and involved "actor" role (Svinicki and Dixon 1987). The goal is to change the student who is inactively-possibly both physically and mentally-sitting in class taking notes and receiving information without thinking or learning very much, into an actively involved student who is mentally engaged and a participant in the learning process.

Active learning can extend to the exams in a course. Professors can use case scenarios analogous to ones discussed in class instead of essay questions to test students' knowledge of concepts and theories as well as their abilities to apply that knowledge to a given situation. For example, in a course on elections, students could be given an election scenario in which they are a candidate and asked to assess their prospects based on a set of conditions outlined in the exam using class and gender analysis. These types of exams stimulate the imagination and can produce more reflective answers than straight essay questions requiring discussion of a theory and an assessment of its strengths and weaknesses.

The active/passive distinction not only has implications for student interest and motivation, but also for learning. As Charles Bonwell has pointed out, "Learning is not a spectator sport. Students do not learn much just sitting in class listening to teachers, memorizing prepackaged assignments, and spitting out an-
Figure 1

\section{Sample Instructional Sequences for Political Classes Using Kolb's Learning Cycle Model}
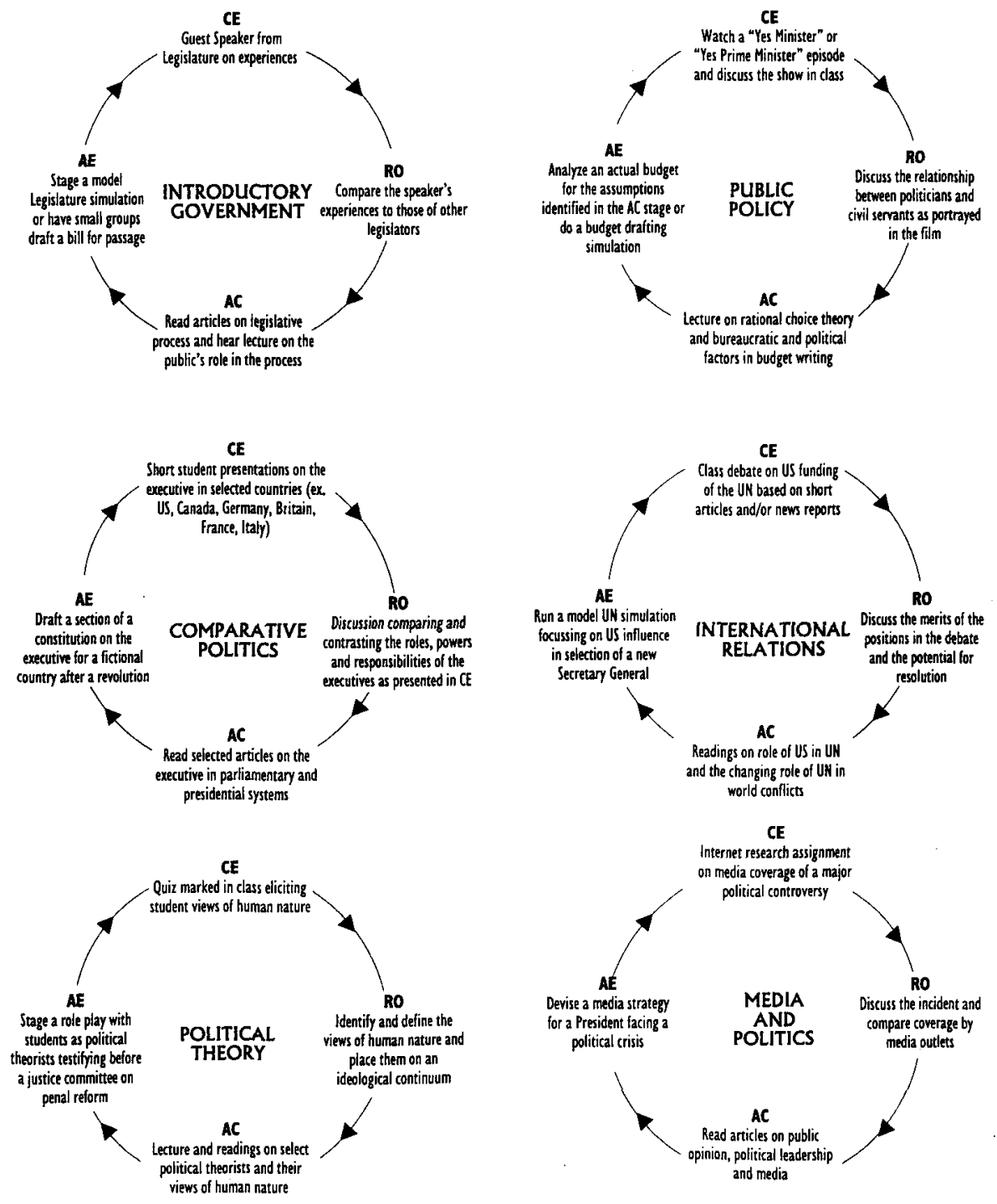

swers. They must talk about what they are learning, write about it, relate it to past experiences, apply it to their daily lives. They must make what they learn part of themselves" (1992/93, 1; cf. Bonwell and Eison 1991). Designing a course with assignments that take students through the four stages of Kolb's experiential learning model can help ensure that students are actively involved in the learning process. Only by actively engaging students in political science courses are instructors likely to reach the goal of producing graduates who are effective thinkers and problem solvers.

Learning research frequently cites the following: "Students retain 10 percent of what they read, 26 percent of what they hear, 30 percent of what they see, 50 percent of what they see and hear, 70 percent of what they say, and 90 percent of what they say as they do something" (Stice 1987). ${ }^{8}$ The Kolb experiential learning model ensures that students have ample opportunities to read, listen, see, talk, and do.

\section{Examples of the Complete Learning Cycle} for Political Science Classes

Throughout this article we gave examples from an election class to illustrate how instructors might develop exercises that take students through the complete cycle. Figure 1 
provides six other sample teaching/ learning sequences. Four of the suggestions fit introductory government, comparative, international relations, and political theory courses and two apply to more advanced courses, but the examples are interchangeable between fields with minor adaptations. These examples are designed to stimulate the teaching creativity of professors in political science.

\section{Summary and Conclusion}

The four learning stages are best used in the order in which they were introduced in this article. The first step, concrete experience, breaks students out of their accustomed passivity and gets them involved in and relating to the learning experience. The second step, reflective observation, further engages the students' minds and fosters development of the intellectual patience and discipline students need to understand what problem the proffered or derived solution best addresses. The third step, abstract conceptualization, helps students develop methods for synthesizing and prioritizing the hundreds of facts and opinions they encounter throughout a course. The instructor can introduce this stage of learning in the first class by mapping the main topics of the course (e.g., writing eight to twelve central topics or course units in the form of a concept tree or in parallel, related, or connected boxes), or throughout the course by interspersing master lectures linking disparate themes. Doing either will help students gain a better sense of what the course entails and how the parts are related. The fourth step, active experimentation, helps students, who are naturally theory-centered and reactive, to learn to take action and to get their hands dirty by offering opportunities to test ideas and observations. This step brings the class back to the beginning of the cycle.

While there is great merit in following Kolb's order through the four stages, the purpose of the model is not to set a rigid learning pattern. Rather, the model conveniently summarizes both the stages of effective learning and the learning preferences so that each can be incorporated into course design and requirements. The model allows classroom learning experiences to be structured and planned, or spontaneous and flexible, or both. What is important is that opportunities are provided for all four learning stages and that students with each of the learning preferences have the opportunity to use their preferred style and develop the other three.

At each learning stage, students with the corresponding learning preference will excel. This has the dual benefit of allowing students to serve as role models for each other and of increasing individual students' self-confidence for learning the new skills. Students learn to value their own gifts as well as those of their peers. The Kolb model stimulates students regardless of their learning preference and challenges them to develop and build all the skills necessary for effective thinking and problem solving.

The explicit consideration of learning preferences in the teaching of political science courses, especially undergraduate courses, may help to reduce declining enrollments experienced by so many departments. If students with a variety of learning preferences can be attracted to the introductory courses and kept interested, the number of political science majors may increase. Instructors may also find that attracting students with a range of learning preferences brings a variety of interesting perspectives to their classes as students actively participate in learning. The exchange of perspectives and approaches will enhance students' educational experiences. These new perspectives may help to broaden and invigorate the discipline of political science while making teaching both fun and interesting.

\section{Notes}

\footnotetext{
* Thanks to Norman Cameron and James M. Lang for their helpful suggestions and to Sherry Howse for her technical assistance.

1. The full Myers Briggs Type Instrument (MBTI) is a sophisticated instrument that is available to trained individuals from Prometheus Nemesis Publishers, P.O. Box 2748, Del Mar, CA 92104. The Keirsey and Bates (1984) book contains a shortened version of the MBTI. Neither instrument is in the public domain. Some schools, like Butler University, are administering the MBTI to students and providing class profiles to instructors to help them adapt their teaching styles to students' learning preferences.

2. The Edmonds Learning Style Identification Exercise (ELSIE) is described in detail in Reinert's article, with complete instructions for using this public-domain document in the classroom. ELSIE groups individuals by preferences for learning by visualization, reading, listening, or activity.

3. Instructors do not need to know their own learning preference in order to design
}

courses and select teaching methods for the full range of preferences. Instructors wishing to complete the Learning-Style Inventory (LSI) can probably obtain a copy from their institution's guidance office or can order one from McBer \& Co. 116 Huntington Ave., \#400, Boston, MA 02116. The LSI is not in the public domain.

4. The learning preference a student (or instructor) chooses is influenced by (a) personality and natural tendencies toward reflection or action; (b) academic training, including early experiences of being taught how to learn as well as more specific training in an academic discipline; (c) career choice, where specialized learning environments and standards of conduct prevail; (d) current job, which requires repetition of certain types of learning activities and may reinforce preferences; and (e) current task, for which preferences may be developed or reinforced (Smith and Kolb 1985).

5. This does not mean that all political scientists have a diverger learning preference; only that it was the most frequent learning preference expressed by political scientists in a Carnegie Commission study of graduate students and faculty (Kolb 1988). In a study of political science students at their university, Fox and Ronkowski noted that political science undergraduates are fairly evenly divided among preferences, but show a slightly greater tendency to identify as assimilators. Lower-level students, in their study, were more likely to identify as divergers than upper-level students (Fox and Ronkowski 1997). The study concludes with a call for teaching styles that accommodate differences in learning preferences.

6. The literature on political science case studies, role plays, and simulations is increasing. Some ideas presented in this article were drawn from Hensley (1993), McIntosh (1994), McQuaid (1992), Pace et al. (1990), Smith and Boyer (1996), Starr (1994), Taylor (1994), Vavrina (1992), and Young and Kopas (1996). Political science simulations include first ministers' conferences, model UN conferences, model parliaments, global and futuris- 
tic models, and the excellent budget exercise offered by Young and Kopas. Vavrina offers a simulation for learning another language as well as politics. Other articles can be found by searching political science literature data bases. A number of web sites are devoted to this topic. For a collection of viewpoints on

\section{References}

Bonwell, Charles C. 1992/93. "Risky Business: Making Active Learning a Reality." Teaching Excellence: POD Network in Higher Education Essay Series.

- , and James A. Eison. 1991. Active Learning: Creating Excitement in the Classroom. ASHE-ERIC Higher Education Reports, Report 1. Washington, DC: George Washington University.

Cameron, Beverly J. 1993. Teaching at the University of Manitoba: A Handbook. Winnipeg: University Teaching Services, University of Manitoba.

-. 1997. "Active and Cooperative Learning Strategies for the Economics Classroom." In Teaching Undergraduate Economics: $A$ Handbook for Instructors, ed. William B. Walstad and P. Saunders. New York: McGraw-Hill.

Felder, Richard M., and Linda K. Silverman. 1988. "Learning and Teaching Styles in Engineering Education." Engineering Education 78(April): 674-81.

Fox, Richard L., and Shirley A. Ronkowski. 1997. "Learning Styles of Political Science Students." PS: Political Science and Politics 30(December): 732-37.

Grasha, Anthony. 1997. How to Become an OSCAR Winning Teacher. Norfolk, VA: Virginia Tidewater Consortium for Higher Education National University Telecommunications Network.

Hensley, Thomas R. 1993. "Come to the Edge: Role Playing Activities in a Consti- effective learning and group work, see Cameron $(1993,1997)$

7. The year I took my first economics course in university, the Canadian dollar took a major tumble. When we asked the professor to explain this, he replied "Don't worry. It's not on the exam." I have never forgotten the chill that went through the room and now, as an instructor, I always begin each lecture with a discussion of current political events.

8 . These results are from a study by the Socony-Vacuum Oil Company. Interested individuals might also consult Felder and Silverman (1988). tutional Law Class." PS: Political Science and Politics 26(March): 64-68.

Keirsey, David, and Marilyn M. Bates. 1984. Please Understand Me: Character and Temperament Type. 5th ed. Del Mar, CA: Prometheus Nemesis.

Kolb, David A. 1976. "Management and the Learning Process." California Management Review 18(3): 22-31.

-. 1984. Experiential Leaming: Experience as the Source of Learning and Development. Englewood Cliffs, NJ: Prentice-Hall.

—. 1988. "Learning Styles and Disciplinary Differences." In The Modern American College, ed. A.W. Chickering and Associates. San Francisco: Jossey-Bass.

Kruzich, J.M., B.J. Friesen, and D. Van Soest. 1986. "Assessment of Student and Faculty Learning Styles: Research and Application." Journal of Social Work Education 22(Fall): 22-30.

McIntosh, Daniel. 1994. "Political Economy in a Lunar Colony: A Simulation of the Relationship between Technology and Politics." PS: Political Science and Politics 27(December): 706-07.

McQuaid, Kathleen. 1992. "The Use of Guided Simulations in the Introductory Level American Politics and State and Local Politics Courses." PS: Political Science and Politics 25(September): 532-34.

Pace, David, Bill Bishel, Roger Beck, Peter Holquist, and George Makowski. 1990. "Structure and Spontaneity: Pedagogical
Tensions in the Construction of a Simulation of the Cuban Missile Crisis." The History Teacher 24(November): 53-65.

Reinert, H. 1976. "One Picture is Worth 1000 Words? Not Necessarily!" Modern Language Journal 60(April): 160-68.

Smith, Donna M., and David A. Kolb. 1985. User's Guide for the Learning-Style Inventory: A Manual for Teachers and Trainers. Boston: McBer.

Smith, Elizabeth T., and Mark A. Boyer. 1996. "Designing In-Class Simulations." PS: Political Science and Politics 29(December): 690-94.

Starr, Paul. 1994. "Seductions of Sim: Policy Simulation Game." American Prospect 17: 19-29.

Stice, J.E. 1987. "Using Kolb's Learning Cycle to Improve Student Learning." Engineering Education. 77(February): 291-96.

Svinicki, M.D., and N. M. Dixon. 1987. "The Kolb Model Modified for Classroom Activities." College Teaching 35(December): 141-46.

Taylor, Andrew J. 1994. "Teaching Politics Panoramically: American Government and the Case Method." PS: Political Science and Politics 27(September): 535-37.

Vavrina, Vernon J. 1992. "From Poughkeepsie to Peoria to the Persian Gulf: A Novice's ICONS Odyssey." PS: Political Science and Politics 25(December): 700-02

Young, Lisa, and Paul Kopas. 1996. Hard Times, Tough Choices: A Political DecisionMaking Simulation. Scarborough, Ontario: Prentice-Hall. 